\title{
The PML-associated protein DEK regulates the balance of H3.3 loading on chromatin and is important for telomere integrity
}

\author{
Kristina Ivanauskiene, ${ }^{1}$ Erwan Delbarre, ${ }^{1}$ James D. McGhie, ${ }^{2}$ Thomas Küntziger, ${ }^{1}$ \\ Lee H. Wong, ${ }^{2}$ and Philippe Collas ${ }^{1}$ \\ ${ }^{1}$ Stem Cell Epigenetics Laboratory, Institute of Basic Medical Sciences, Faculty of Medicine, and Norwegian Center for Stem Cell \\ Research, University of Oslo, 0317 Oslo, Norway; ${ }^{2}$ Epigenetics and Chromatin (EpiC) Research, Department of Biochemistry \\ and Molecular Biology, Monash University, Clayton, VIC 3800, Australia
}

\begin{abstract}
Histone variant H3.3 is deposited in chromatin at active sites, telomeres, and pericentric heterochromatin by distinct chaperones, but the mechanisms of regulation and coordination of chaperone-mediated H3.3 loading remain largely unknown. We show here that the chromatin-associated oncoprotein DEK regulates differential HIRA- and DAAX/ ATRXdependent distribution of $\mathrm{H} 3.3$ on chromosomes in somatic cells and embryonic stem cells. Live cell imaging studies show that nonnucleosomal H3.3 normally destined to PML nuclear bodies is re-routed to chromatin after depletion of DEK. This results in HIRA-dependent widespread chromatin deposition of H3.3 and H3.3 incorporation in the foci of heterochromatin in a process requiring the DAXX / ATRX complex. In embryonic stem cells, loss of DEK leads to displacement of PML bodies and ATRX from telomeres, redistribution of $\mathrm{H} 3.3$ from telomeres to chromosome arms and pericentric heterochromatin, induction of a fragile telomere phenotype, and telomere dysfunction. Our results indicate that DEK is required for proper loading of ATRX and H3.3 on telomeres and for telomeric chromatin architecture. We propose that DEK acts as a "gatekeeper" of chromatin, controlling chromatin integrity by restricting broad access to H3.3 by dedicated chaperones. Our results also suggest that telomere stability relies on mechanisms ensuring proper histone supply and routing.
\end{abstract}

[Supplemental material is available for this article.]

Loading of histone variant H3.3 on chromatin occurs independently of DNA synthesis and is enabled by dedicated histone chaperones (Szenker et al. 2011; Filipescu et al. 2013). Among these, histone cell cycle regulator (HIRA) acts in a complex with ubinuclein 1 and 2 (UBN1 and UBN2) (Tagami et al. 2004; Elsaesser and Allis 2010) to mediate incorporation of $\mathrm{H} 3.3$ at gene bodies and promoters (Goldberg et al. 2010; Banaszynski et al. 2013; Pchelintsev et al. 2013), and at sites of DNA damage (Adam et al. 2013). HIRA has also been shown to play a nucleosome "gap filling" role in DNA to maintain chromatin integrity (Ray-Gallet et al. 2011; Schneiderman et al. 2012), implicating HIRA in widespread H3.3 deposition. In heterochromatin, death-domain associated protein (DAXX), together with alpha thalassemia/mental retardation syndrome X-linked (ATRX), a chromatin remodeler (Gibbons et al. 1997; Argentaro et al. 2007), loads H3.3 on pericentric chromatin and, in embryonic stem cells (ESCs), on telomeres (Drane et al. 2010; Goldberg et al. 2010; Lewis et al. 2010; Wong et al. 2010; Eustermann et al. 2011; Chang et al. 2013). Further, we have shown that DAXX, independently of ATRX, also recruits a pool of nonnucleosomal H3.3 to promyelocytic leukemia (PML) nuclear bodies (NBs) before deposition in chromatin (Delbarre et al. 2013).

PML NBs are involved in many nuclear processes including post-translational modifications and transcription regulation (Bernardi and Pandolfi 2007). The main organizer of PML NBs is the PML protein (de Thé et al. 2012). PML recruits many proteins to NBs, a process often requiring mutual sumoylation (Lallemand-

\footnotetext{
Corresponding authors: philippe.collas@medisin.uio.no, lee.wong@ monash.edu

Article published online before print. Article, supplemental material, and publication date are at http://www.genome.org/cgi/doi/10.1101/gr.173831.114.
}

Breitenbach et al. 2001; de Thé et al. 2012). PML NBs also interact with chromosomes (Ching et al. 2013) and, in ESCs, are involved in maintaining telomeric chromatin integrity (Chang et al. 2013). There, PML NBs serve as platforms tethering ATRX and H3.3 at telomeres, and depletion of PML, ATRX, or H3.3 causes a telomeric dysfunction phenotype (Wong et al. 2009, 2010; Chang et al. 2013). These observations point to functional interactions between PML, ATRX, and H3.3 important for the regulation of chromatin integrity at telomeres. Other histone chaperones including HIRA and ASF1A have also been implicated in chromatin stability at these sites (Jiang et al. 2011; O'Sullivan et al. 2014), suggesting that several H3.3 chaperones cooperate locally to establish telomere chromatin architecture. The question remains, however, of what determines the extent of cooperation of histone chaperones in the formation and maintenance of different chromatin environments.

The oncoprotein DEK has been shown to act as another H3.3 chaperone in vitro and in Drosophila cells (Sawatsubashi et al. 2010). DEK is a nonhistone chromosomal protein with no identified enzymatic activity (Kappes et al. 2001; Privette Vinnedge et al. 2013). DEK binds DNA with no sequence specificity but with a preference for unconventional DNA conformations such as supercoiled or cruciform DNA (Waldmann et al. 2003; Bohm et al. 2005). DEK can bend DNA and introduce positive supercoils (Waldmann et al. 2002) and is important for heterochromatin integrity by enhancing binding of CBX3 (also known as HP1 gamma homolog) to histone

\footnotetext{
(c) 2014 Ivanauskiene et al. This article is distributed exclusively by Cold Spring Harbor Laboratory Press for the first six months after the full-issue publication date (see http://genome.cshlp.org/site/misc/terms.xhtml). After six months, it is available under a Creative Commons License (Attribution-NonCommercial 4.0 International), as described at http://creativecommons.org/licenses/by-nc/4.0/.
} 
H3 trimethylated on lysine 9 (H3K9me3) (Kappes et al. 2011; Saha et al. 2013). In addition, the identification of DEK and DAXX in a complex with histone deacetylase 2 (Hollenbach et al. 2002) suggests cooperation between histone chaperones in the regulation of transcriptionally repressive chromatin. These observations collectively suggest a role of DEK in regulating heterochromatin architecture; however, the extent to which DEK is involved in controlling H3.3 deposition on chromatin is unknown.

Here, we demonstrate a new and important function of DEK in the maintenance of chromatin integrity by controlling entry sites of H3.3 into chromatin. We show that nonnucleosomal H3.3 destined to PML NBs is redirected to chromatin after depletion of DEK, with domain specificity dependent on HIRA or the DAXX/ ATRX complex. Loss of DEK in ESCs causes dissociation of PML NBs and ATRX from telomeres, impairs H3.3 loading at these sites, and disrupts telomeric chromatin integrity. In the context of mechanisms underlying the formation of architectural chromatin domains, our results point to a role for DEK as a gatekeeper of chromatin, controlling DNA access to histones such as H3.3.

\section{Results}

\section{DEK associates with PML nuclear bodies}

We have recently reported in human mesenchymal stem cells (MSCs) the association of the H3.3 chaperones DAXX, ATRX, and HIRA with PML NBs, along with H3.3 itself (Delbarre et al. 2013). We now show that DEK, another H3.3 chaperone, also associates with $60.2 \%$ ( \pm 18 ) of PML NBs (Fig. 1A; Supplemental Fig. 1A) and with NBs formed after EGFP-PML overexpression (Fig. 1B). DEK does not colocalize with TERF2 or CENPA (also known as CenH3) (Supplemental Fig. 1B), indicating that DEK is excluded from telomeres and centromeres, respectively, in these cells. PML and DEK coimmunoprecipitate using anti-PML or anti-DEK antibodies, indicating that both proteins exist in a complex at PML NBs (Fig. 1C). Most proteins contained within PML NBs contain a SUMO-interacting motif essential for targeting to PML (de Thé et al. 2012). When searching for functional sites in the protein motif identification databases PROSITE Scan (http://prosite.expasy.org) (Sigrist et al. 2013) and Eukaryote Linear Motif resource (http://elm.eu.org) (Dinkel et al. 2014), we found that DEK contains an $\mathrm{A}^{260} \mathrm{KRE}^{263}$ motif fitting the [VILAMPF] KX[ED] signature recognized by SUMO1. This finding is consistent with our results showing an association of DEK with PML NBs.

\section{Depletion of DEK redistributes $\mathrm{H} 3.3$ into heterochromatin foci as a DAXX/ ATRX-dependent process}

The report of DEK as an H3.3 chaperone (Sawatsubashi et al. 2010) prompts the question of how DEK might affect H3.3 distribution in chromatin. To test this, we knocked down DEK by siRNA (Supplemental Fig. 2A) and examined the distribution of H3.3 fused to mCherry (H3.3-mC) $48 \mathrm{~h}$ after transfection. In control cells, H3.3$\mathrm{mC}$ is deposited into chromatin and displays foci at PML NBs (Fig. 2A), in line with our earlier findings (Delbarre et al. 2013). In the absence of DEK, H3.3-mC forms fewer (one to three) but larger foci $\left(P=1.54 \times 10^{-8}\right.$; Wilcoxon rank-sum test) also associated with PML (Fig. 2A,B). Unlike in DEK-containing cells, these H3.3 foci consistently coincide with dense DAPI staining and are enriched in H3K9me3 (Fig. 2C; Supplemental Fig. 2B) and CBX3 (Supplemental Fig. 2C), indicating enrichment in heterochromatin. H3.3-mC foci are not associated with telomeres (not shown) and thus do not correspond to alternative lengthening of telomere (ALT)-associated PML bodies (Jiang et al. 2011). Association of H3.3-mC with H3K9me3-enriched chromatin in DEK-depleted cells is reduced after knockdown of $D A X X$ or $A T R X$, but not HIRA, despite the persistence of H3K9me3 in heterochromatin foci (Fig. 2D,E). Similar results were obtained when we examined CBX3 as another heterochromatin mark (Supplemental Fig. 2D). We conclude that DEK depletion results in DAXX/ATRX-dependent localization of H3.3 in heterochromatin foci that are associated with large PML NBs.

We next examined the role of PML in the localization of H3.3$\mathrm{mC}$ at heterochromatin foci in DEK-depleted cells. $P M L$ and $D E K$ were simultaneously knocked down by siRNA. After $4 \mathrm{~d}$ under knockdown conditions, H3.3-mC was transfected simultaneously to a second round of PML and DEK knockdown. After $48 \mathrm{~h}$, we find that DEK and PML depletion does not abrogate H3.3-mC detection in heterochromatin foci, which remain enriched in H3K9me3 and CBX3 (Supplemental Fig. 2E,F). Thus, PML is dispensable for the relocalization of H3.3 to heterochromatin foci in the absence of DEK and for the retention of $\mathrm{H} 3.3$ at these sites. This reinforces the view that loss of DEK favors an enrichment of H3.3 in foci of heterochromatin in
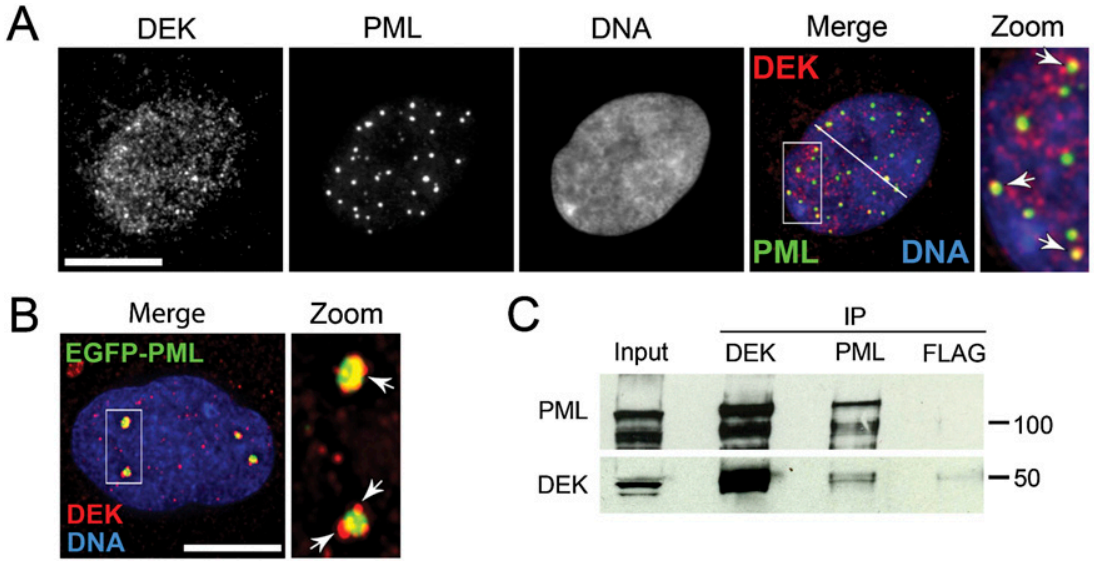

C

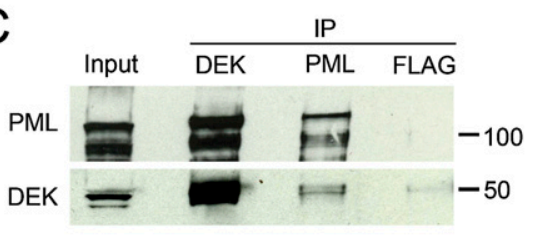

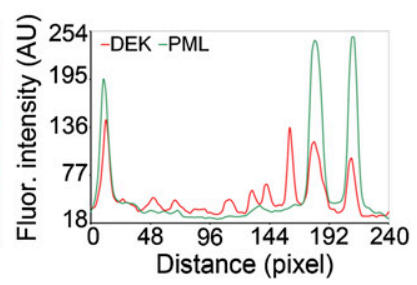

Distance (pixel)

Figure 1. DEK associates with PML NBs. $(A)$ Immunofluorescence localization of DEK and PML in nuclei of human MSCs. Graph shows fluorescence intensity of PML and DEK along the line drawn on the merged image. (B) Immunofluorescence localization of DEK in cells expressing EGFP-PML. Arrows point to sites of DEK and PML colocalization. Bars, $10 \mu \mathrm{m}$. (C) Western blot analysis of PML and DEK immune precipitates (IP) from MSC lysates. Control immunoprecipitations were done using an anti-FLAG antibody. 
A

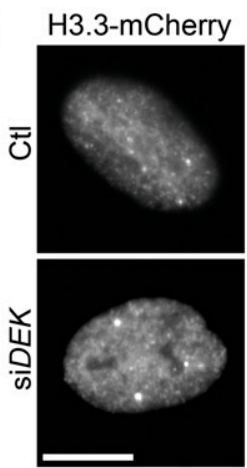

C
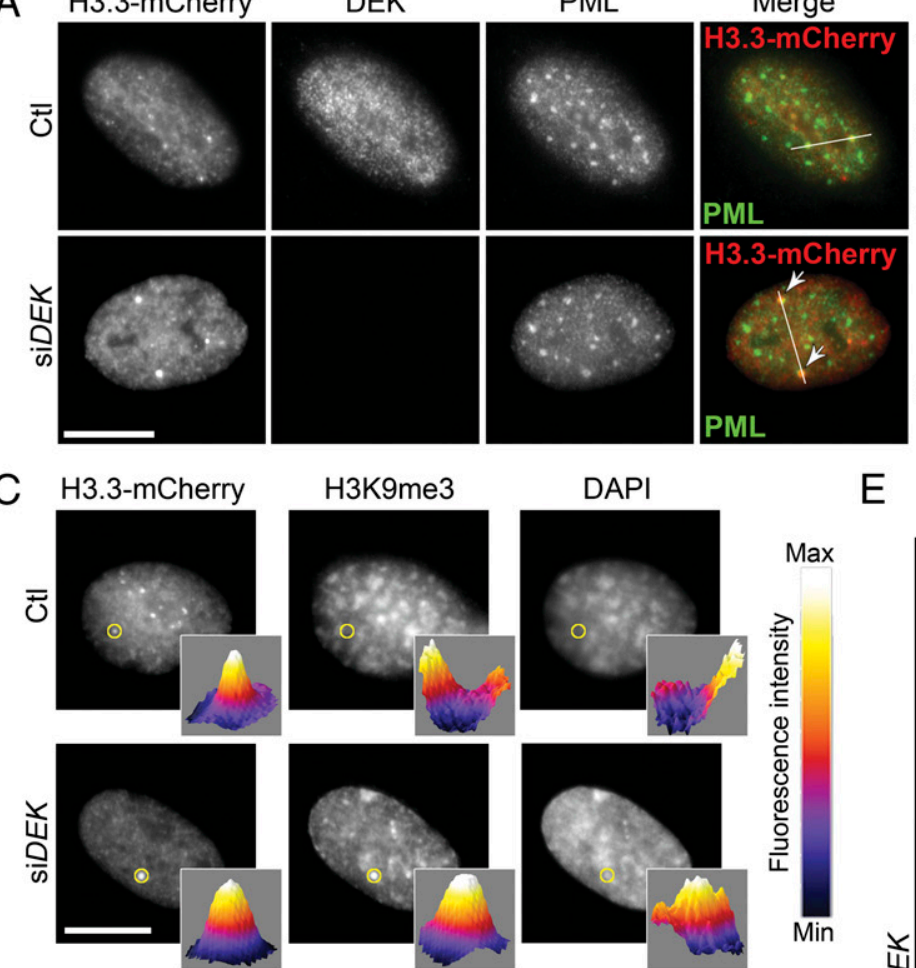

DAPI

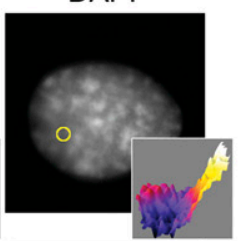

D

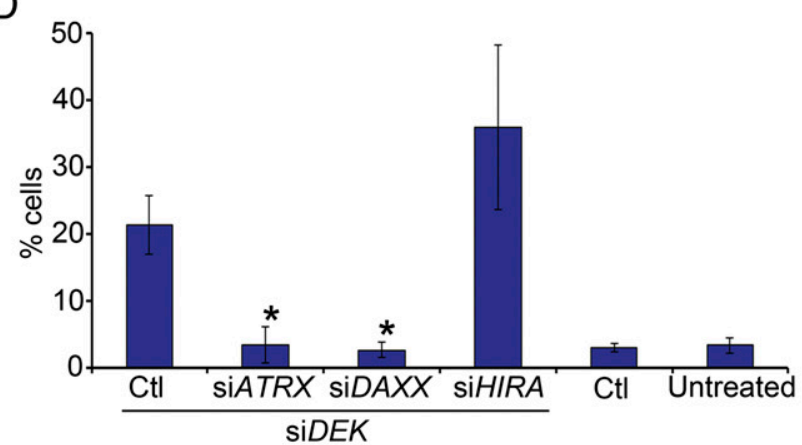

E

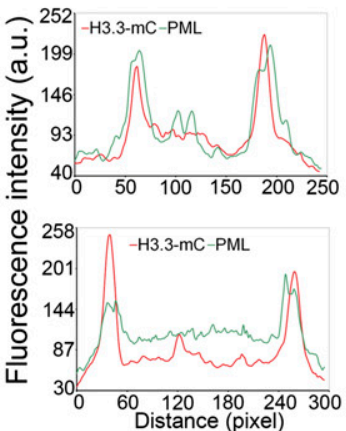

B
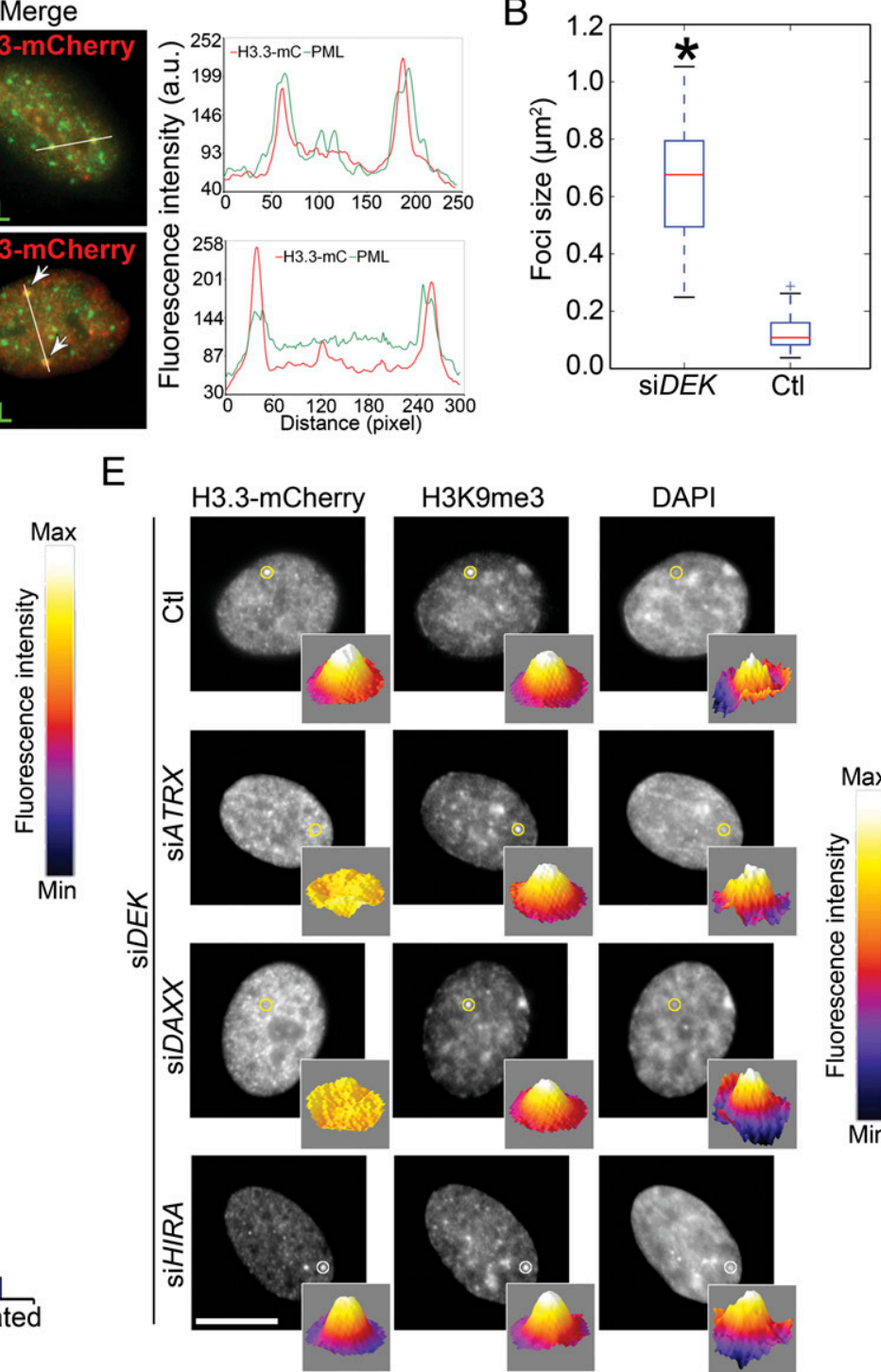
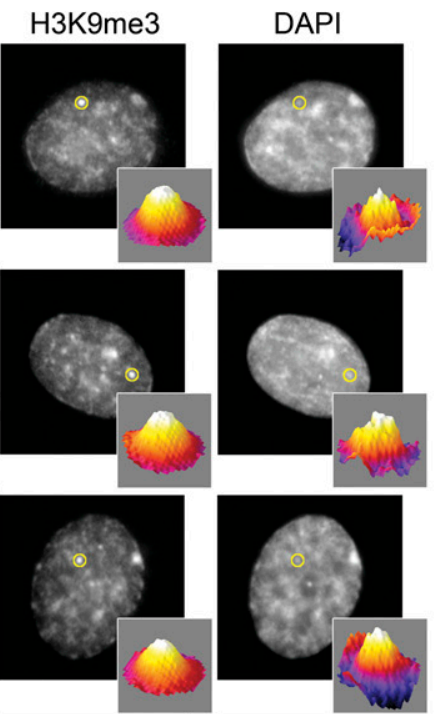

$\operatorname{Max}$
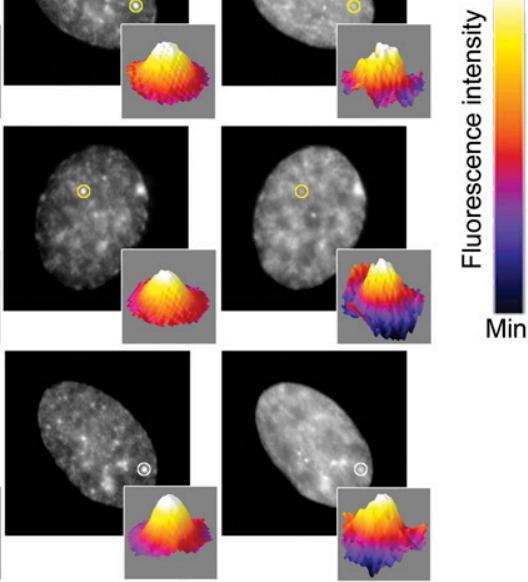

Figure 2. Depletion of DEK inhibits recruitment of H3.3-EGFP to PML NBs and promotes its loading on chromatin. $(A) \mathrm{H} 3.3$ forms large foci colocalizing with PML after DEK depletion. Localization of H3.3-mCherry, DEK, and PML in control (Ctl) and DEK-depleted (siDEK) cells, $48 \mathrm{~h}$ after H3.3-mC transfection. DEK was knocked down for $4 \mathrm{~d}$ by siRNA, at which time H3.3-mC was transfected concomitantly with a second round of DEK knockdown. (B) Median area of H3.3-mC foci in control and DEK-depleted cells. $\left(^{*}\right) P=1.54 \times 10^{-8}$ (Wilcoxon rank-sum test). Quantification of $\mathrm{H} 3.3-\mathrm{mC}$ foci as "large" arbitrarily required an area $\geq 0.3 \mu \mathrm{m}^{2}$. (C) DEK depletion results in coenrichment of H3.3-mC foci in H3K9me3 and DAPI-dense DNA (100\% of large H3.3$\mathrm{mC}$ foci). Localization of H3.3-mC, H3K9me3, and DAPI intensity in control and DEK-depleted cells, with three-dimensional plots of H3.3-mC, H3K9me3, and DAPI intensity levels in control and DEK-depleted cells (circled area on the images). Scale: gray levels in arbitrary units; scale is identical within the marks analyzed. (D) Percentage of cells with $\mathrm{H} 3.3-\mathrm{mC}$ localized at heterochromatic foci marked by $\mathrm{H} 3 \mathrm{~K} 9 \mathrm{me} 3$ in DEK-depleted cells also treated with siRNA to ATRX, DAXX, or HIRA. Data for control-transfected and untreated cells are also shown (right). $\left(^{*}\right) P<10^{-4}$, Fisher's exact test; mean \pm SD of 200 cells per condition. (E) Localization of H3.3-mC, H3K9me3, and DAPI intensity in DEK-depleted cells also knocked down of ATRX, DAXX, or HIRA, with threedimensional intensity plots as in C. Plots in C and $E$ were generated using Image). Note the lower H3.3 enrichment at these foci after knockdown of $A T R X$ or $D A X X$, but not HIRA, despite the maintenance of the H3K9me3 and DAPI-dense marks. Bars, $10 \mu \mathrm{m}$.

a process mediated by the DAXX/ATRX complex. What leads to aggregation of PML NBs at these sites remains unknown.

DEK restricts broad incorporation of $\mathrm{H} 3.3$ into chromatin and favors its recruitment to PML NBs

We have previously shown that H3.3 is transiently recruited to PML NBs in a DAXX-dependent manner (Delbarre et al. 2013). The PML-independent H3.3 accumulation in foci of heterochromatin associated with PML NBs we observed after DEK depletion prompts the question of whether H3.3 is actively recruited to these bodies in the absence of DEK. To address this, we examined the mobility of H3.3-EGFP by fluorescence recovery after photobleaching (FRAP) at foci of H3.3-EGFP formed at PML NBs. Photobleaching of H3.3EGFP at PML NBs in DEK-containing cells leads to partial but fast EGFP fluorescence recovery at these sites, reflecting recruitment of a soluble pool of H3.3 (Fig. 3A, green line). DEK knockdown, however, strikingly abolishes recovery of H3.3-EGFP (Fig. 3A, purple line), indicating that it is no longer recruited to PML NBs. Thus, loss of DEK impairs the mobility of H3.3-EGFP at PML NBs. 
A

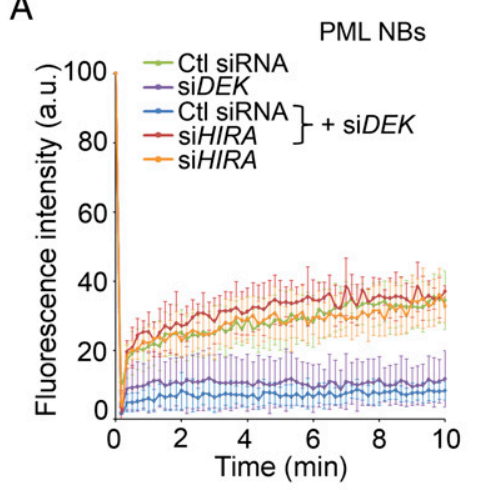

C

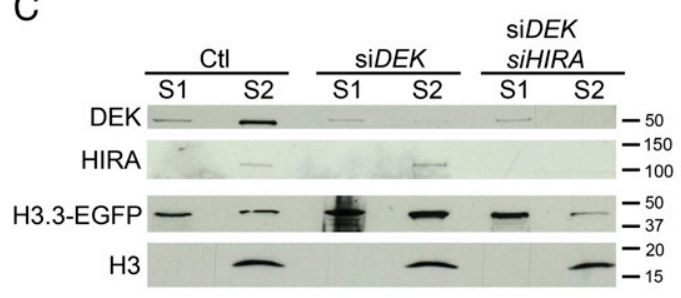

B

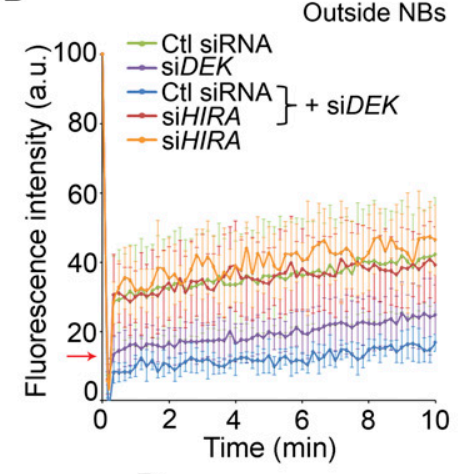

D
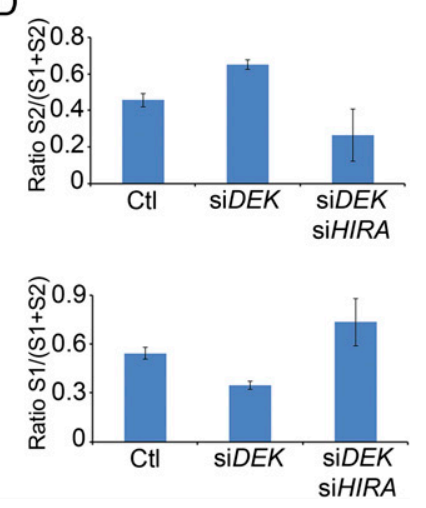

Figure 3. Depletion of DEK inhibits recruitment of H3.3-EGFP to PML NBs and promotes its loading on chromatin. (A) Loss of DEK by siRNA inhibits targeting of H3.3-EGFP to PML NBs. FRAP analysis of H3.3 EGFP at PML NBs $48 \mathrm{~h}$ after H3.3-EGFP transfection, in control and DEK-depleted cells (green and purple lines; mean \pm SD of eight to 10 cells). H3.3-EGFP was also bleached in cells that were also depleted of HIRA as indicated (blue, red, and orange lines; mean \pm SD of five to seven cells). Loss of HIRA restores the soluble pool of H3.3-EGFP sequestered after DEK depletion (cf. red and blue lines). (B) FRAP analysis of H3.3-EGFP outside NBs $48 \mathrm{~h}$ post-transfection in control and DEK-depleted cells. DEK depletion reduces the pool of soluble H3.3-EGFP (purple line; red arrow, recovery of soluble H3.3-EGFP $10 \mathrm{sec}$ after bleaching) (nine to 14 cells). Cells were also depleted of HIRA as indicated (blue, red, and orange lines; five to six cells). (C) Western blot analysis of distribution of H3.3-EGFP in cells treated with control siRNA or siRNA to DEK or $D E K+H I R A$. Cells were fractionated into a $0.5 \%$ Triton X-100-soluble fraction (S1) and an MNase-soluble nucleosomal fraction (S2) (see also Supplemental Fig. 3C). (D) Densitometry analysis of H3.3-EGFP enrichment in S2 and S1 fractions (mean \pm SD from duplicate experiments).

We infer from these data either that DEK interferes with the DAXX-dependent targeting of H3.3 to PML NBs, or that DEK promotes the maintenance of a soluble pool of H3.3, perhaps by configuring chromatin in a way that prevents its incorporation. Testing these alternatives, we found that inhibition of H3.3-EGFP recovery at PML NBs after DEK depletion is rescued by overexpression of $D A X X$ (Supplemental Fig. 3A). This concurs with the persistence of DAXX at PML NBs in these cells (Supplemental Fig. 3B) and indicates that the DAXX-dependent machinery of H3.3 recruitment to PML NBs (Delbarre et al. 2013) remains functional in the absence of DEK. Thus we next determined the impact of $D E K$ knockdown on H3.3-EGFP mobility at random sites outside PML NBs. Based on our earlier findings (Delbarre et al. 2013), H3.3-EGFP fluorescence signal in these areas originates both from H3.3-EGFP loaded on chromatin and from a pool of soluble H3.3-EGFP. In the absence of DEK, the highly mobile fraction of H3.3-EGFP is diminished (Fig. 3B, purple line, red arrow), indicating a reduction in the soluble pool of H3.3 available for targeting to PML NBs, and prompt loading of H3.3 on chromatin. These results, therefore, suggest a role for DEK in preventing incorporation of H3.3 into chromatin regions from which it should be excluded.
Depletion of DEK enhances widespread HIRA-dependent loading of H3.3 on chromatin

HIRA has been shown to play a role in filling nucleosome gaps on DNA by loading H3.3, presumably to maintain chromatin integrity (Ray-Gallet et al. 2011). Thus, we tested whether HIRA would be responsible for a widespread loading of H3.3 on chromatin in the absence of DEK, as highlighted by our FRAP results. We knocked down HIRA in DEKdepleted cells and monitored recovery of H3.3-EGFP after photobleaching outside PML NBs. Figure 3B shows that loss of HIRA restores the sharp recovery of H3.3EGFP (red line), which corresponds to the soluble fraction of H3.3-EGFP depleted by the loss of DEK. We infer from these results that HIRA depletion prevents the overloading of H3.3 on chromatin occurring in the absence of DEK. As expected, loss of HIRA in DEK-depleted cells also restores recovery of H3.3-EGFP at PML NBs (Fig. 3A, red line). Of note, in control cells HIRA knockdown does not affect H3.3-EGFP recovery at and outside PML NBs (Fig. 3A,B, yellow line). These results show that the loss of DEK results in a rerouting of newly synthesized H3.3 from PML NBs to broad chromatin areas in a HIRA-dependent manner. To our knowledge, this is the first evidence of a chromatin protein (DEK) modulating H3.3 deposition.

To further test this mechanism, we fractionated MSCs expressing H3.3-EGFP into a $0.5 \%$ Triton X-100-soluble fraction (S1) and a micrococcal nuclease (MNase)soluble nucleosome fraction (S2), and examined the distribution of H3.3-EGFP in these fractions before and after DEK depletion. Immunoblotting analysis shows that loss of DEK results in a reduced proportion of H3.3-EGFP in the Triton $\mathrm{X}-100$ soluble fraction (S1) and in an enhanced fraction of H3.3EGFP in MNase-soluble nucleosomes (S2) (Fig. 3C,D). Moreover, knockdown of HIRA in DEK-depleted cells (see Supplemental Fig. 3C) increases the Triton X-100-soluble pool of H3.3-EGFP (Fig. 3C, D), in complete agreement with the FRAP data. Collectively, our results indicate that removal of DEK from chromatin favors incorporation of H3.3, and that the major part of this process is mediated by HIRA. The presence of DEK contributes to maintaining a soluble pool of H3.3 available for recruitment to PML NBs.

In embryonic stem cells, loss of DEK leads to relocalization of H3.3 from telomeres to chromosome arms and pericentric heterochromatin

We have previously shown in mouse ESCs the role of PML in the recruitment of ATRX and H3.3 at telomeres, a process essential to maintaining telomeric chromatin integrity (Chang et al. 
2013). Given the connection between PML, DEK, and H3.3 established in the present study, we examined in mouse ESCs the role of DEK on the PML/ATRX/H3.3 association with telomeres and on telomeric chromatin assembly. We find that in all undifferentiated ESCs, DEK colocalizes with telomeres labeled with the telomeric protein TERF1, together with ATRX and PML (Supplemental Fig. 4A). As noted earlier for the association of PML with telomeres (Chang et al. 2013), not all telomeres harbor DEK (Supplemental Fig. 4A-C). Nonetheless, DEK association with telomeres is specific to undifferentiated ESCs as differentiation leads to DEK dissociation from telomeres (Supplemental Fig. 4B,C). This is in line with our previous observation that telomeres do not contain DEK in MSCs. DEK depletion by siRNA (Supplemental Fig. 4D) strikingly delocalizes both PML and ATRX from telomeres, and elicits strong enrichment of PML and ATRX at sites of pericentric heterochromatin (Fig. 4A; Supplemental
Fig. 4E,F). Thus DEK is required for the association of PML and ATRX with telomeres, providing evidence for a chromatin-based anchor of PML and ATRX.

Given the role of ATRX on H3.3 deposition at telomeres in ESCs (Wong et al. 2010), and the DEK-dependent association of ATRX with telomeres (Supplemental Fig. 4E), we asked whether a loss of DEK would also affect H3.3 enrichment at these sites. To unequivocally examine $\mathrm{H} 3.3$ at these sites, we assessed H3.3 phosphorylated on Ser31 (H3.3S31p) using a phospho-specific antibody (Supplemental Fig. 5A; Wong et al. 2009), as H3.3S31p is enriched on telomeres, but not in pericentric heterochromatin, on mitotic chromosomes in ESCs (Wong et al. 2009). We find that DEK depletion strongly diminishes H3.3S31p labeling at telomeres, indicating reduced $\mathrm{H} 3.3$ loading at these sites (Fig. 4B,C). Thus in ESCs, DEK is also important for targeting H3.3 to telomeres and hence for proper telomeric chromatin assembly within PML NBs at these sites.

A
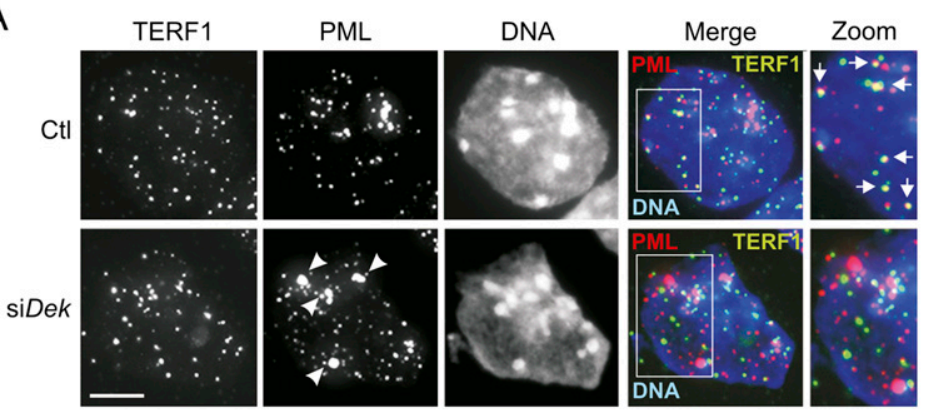

B
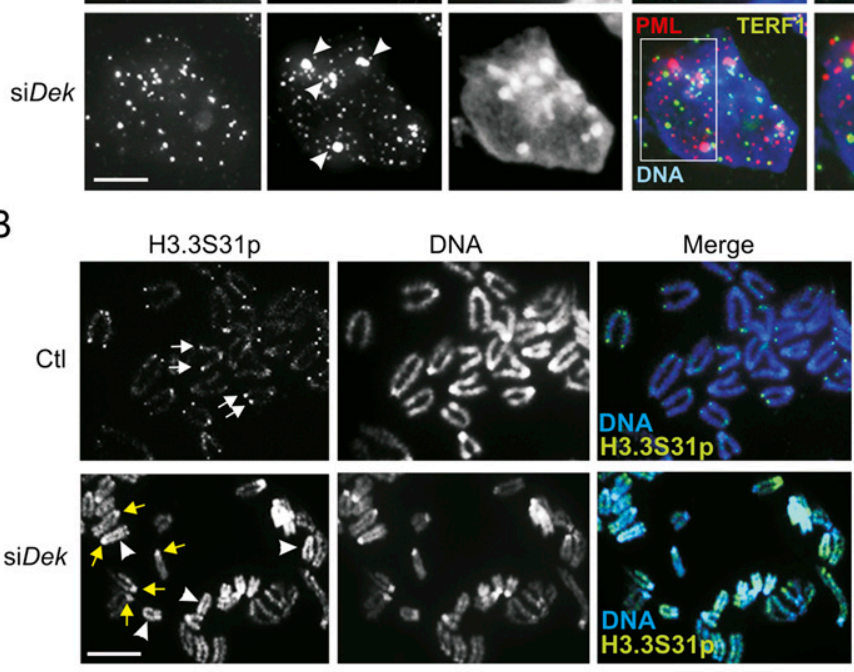

C
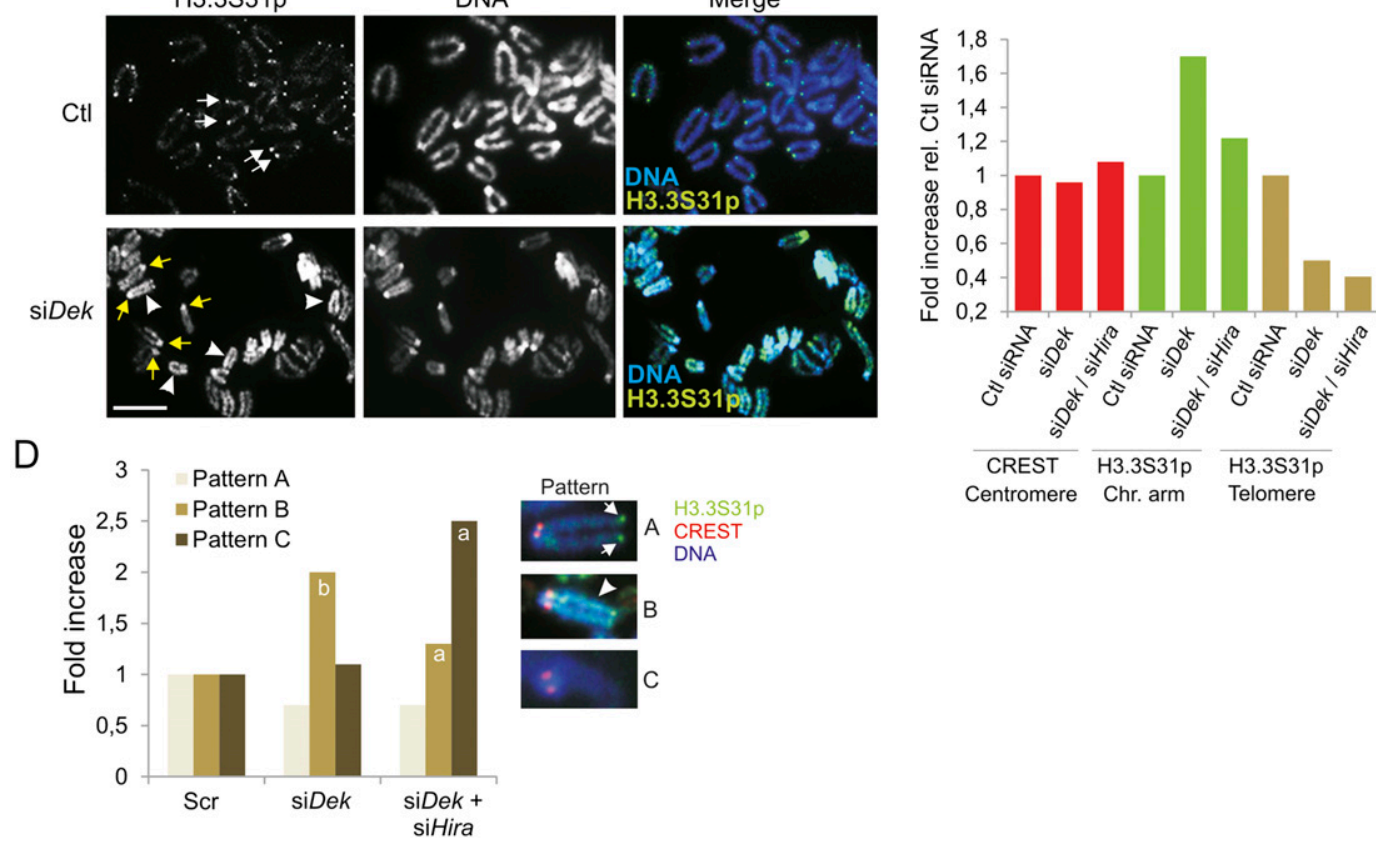

Figure 4. Loss of DEK in ESCs results in displacement of PML from telomeres, reduced H3.3 loading at telomeres, and HIRA-dependent H3.3 deposition on chromosome arms. $(A)$ Immunolocalization of TERF1 and PML in control and DEK-depleted cells. Arrows in Ctl cells point to TERF1-PML colocalization; arrowheads in siDek cells show large PML NBs at sites of heterochromatin. (B) Immunofluorescence localization of H3.3S31p on mitotic chromosomes from control and DEK-depleted cells. Arrows in Ctl cells point to H3.3S31p at telomeres. White arrowheads in the siDek image show H3.3S31p on chromosome arms and yellow arrows show H3.3S31p at pericentromeres. Bars, $5 \mu \mathrm{m}$. (C) Fluorescence intensity level of CREST (as an invariant control marker; see panel $D$ ) and H3.3-EGFP on chromosome arms and centromeres in cells depleted of DEK or DEK + HIRA, relative to control cells (Ctl siRNA). (D) HIRA knockdown in DEK-depleted cells reduces H3.3S31p loading on chromosome arms. Graph shows the fold change in the proportion of metaphases with H3.3S31p patterns " $\mathrm{A}$ " (telomere staining; arrow), " $\mathrm{B}$ " (chromosome arm staining [arrowhead] and/or pericentromeric labeling), and " $\mathrm{C}$ " (no staining). Sixty mitotic spreads were examined. CREST was labeled as a centromere marker. $P<0.001$ relative to Ctl and siDek; $P<0.001$ relative to Ctl (Fisher's exact test). Larger data sets are shown in Supplemental Fig. 6B. 
Strikingly, DEK loss also results in a widespread increase in H3.3S31p staining on chromosome arms (Fig. 4B, white arrowheads; Fig. 4C) and in pericentric regions (Fig. 4B, yellow arrows). These observations are unlikely to result from H3.3 hyperphosphorylation on S31 because the global levels of H3.3S31p on mitotic chromosomes are not affected by overexpression of DEK (Supplemental Fig. 5B). These results indicate that the absence of DEK results in a broad redistribution of H3.3 in chromatin, outside telomeres.

The involvement of HIRA in widespread H3.3 deposition into chromatin in DEK-depleted cells inferred from our earlier experiments suggests that HIRA might also be involved in the aberrant H3.3 localization on chromosome arms observed here. Indeed, knockdown of HIRA (Supplemental Fig. 6A) in DEKdepleted ESCs reduces H3.3S31p detection on chromosome arms (Fig. 4C) and increases the proportion of chromosomes with no detectable H3.3S31p (Fig. 4D; Supplemental Fig. 6B). These results indicate that depletion of DEK in ESCs reduces H3.3 loading at telomeres and instead elicits a HIRA-dependent, broad deposition of $\mathrm{H} 3.3$ on chromosome arms.

We conclude that DEK depletion in ESCs results in the relocalization of PML, ATRX, and H3.3 from telomeres to pericentric heterochromatin, along with widespread H3.3 loading on chromosome arms. This demonstrates the importance of DEK in modulating ATRX/H3.3 targeting to PML NBs and chromatin, and suggests a hitherto unknown role of DEK in regulating H3.3 distribution on telomeric vs. nontelomeric chromatin.

\section{Loss of DEK elicits the formation of fragile telomeres}

Consistent with the previous observations, DEK depletion leads to aberrations in telomere structure detectable on mitotic chromosomes. Under normal conditions, both TERF1 immunolabeling and telomere fluorescence in situ hybridization (FISH) reveal on chromatid ends a single signal of intensity similar to the signal on the sister chromatid (Fig. 5A,B). After DEK depletion, however, most metaphase spreads show stretched or multiple TERF1 signals on at least one of the chromatid ends (Fig. 5A, arrows) and similarly, stretched or multiple telomere FISH signals (Fig. 5B,C). These multiple signals are spatially separated from the chromatid end, consistent with a failure of telomeric DNA to condense and with a fragile telomere phenotype (Sfeir et al. 2009). As this in turn would imply telomeric DNA damage, we next examined any enrichment of telomeres in gamma-H2AX (i.e., H2AX phosphorylated on S139), a marker of DNA damage. We find that DEK depletion results in accumulation of gamma-H2AX in nuclei, including at telomeres (Fig. 5D, arrows), in line with a role of human DEK in regulating DNA damage signaling and repair (Kavanaugh et al. 2011). Telomere-specific enrichment in gamma-H2AX was further demonstrated by chromatin immunoprecipitation (ChIP)qPCR (Fig. 5E). In addition, transcription of the telomere-encoded TERRA noncoding RNA (Luke and Lingner 2009) is enhanced in DEK-depleted cells (Fig. 5F), suggesting a loss of chromatin repression at telomeres.

Altogether, these results point to the formation of fragile telomeres, increased telomere DNA damage, and a telomere dysfunction phenotype elicited by the loss of DEK. These phenotypes may arise from defective ATRX and H3.3 targeting to telomeres. In addition to a hitherto unidentified role of DEK in the regulation of H3.3 loading on telomeric vs. nontelomeric chromatin, we demonstrate a novel function of DEK in regulating proper telomeric chromatin assembly and its structural integrity.

\section{Discussion}

\section{The chromatin-bound protein DEK restricts histone access}

A role of DEK in the maintenance of chromatin architecture by altering DNA topology is well established (Alexiadis et al. 2000; Kappes et al. 2001; Waldmann et al. 2002, 2004). DEK has been associated with DNA supercoiling and bending activities consistent with a role in chromatin compaction (Privette Vinnedge et al. 2013). DEK also promotes heterochromatin formation through its $\mathrm{Su}$ (var) function (Kappes et al. 2011). We now uncover a new role of DEK in maintaining chromatin integrity by controlling the chromatin distribution of H3.3. Live imaging and biochemical fractionation data indicate that the loss of DEK leads to widespread HIRA-dependent loading of H3.3 on chromatin and DAXX/ATRXdependent incorporation of H3.3 in heterochromatin sites. In ESCs, DEK knockdown causes dislocation of PML and ATRX from telomeres, defective H3.3 loading at these sites, fragile telomeres, telomeric DNA damage, and aberrant transcription of the telomere-encoded TERRA RNA. DEK emerges therefore as a hitherto unidentified chromatin-associated factor regulating H3.3 deposition in human and mouse cells and important for telomeric chromatin integrity and function in ESCs.

Our results lead to a model of DEK as a "gatekeeper" of chromatin, with a role in H3.3 deposition depending on cellular and genomic contexts (Fig. 6). Outside telomeres (Fig. 6A), DEK restricts HIRA-mediated widespread deposition of nonnucleosomal H3.3; nonnucleosomal H3.3 is instead targeted to PML NBs by DAXX (Delbarre et al. 2013). Loss of DEK relaxes DNA topology, which may be associated with loss or displacement of nucleosomes (Talbert and Henikoff 2010). Our findings are consistent with a "gap filling" role of HIRA shown to deposit H3.3 on DNA free of nucleosomes in order to reconstitute nucleosomal chromatin (Ray-Gallet et al. 2011). In order to protect chromatin integrity, one function of DEK may be to maintain nucleosome composition by preventing unscheduled histone eviction, incorporation, or exchange. DEK could also function by removing H3.3 steadily deposited by HIRA (in chromosome arms) or by the DAXX/ATRX complex (in heterochromatin). The latter would be consistent with the H3.3 chaperone activity of DEK (Obri et al. 2014). At telomeres and in ESCs (Fig. 6B), DEK ensures proper incorporation of H3.3 by ATRX via PML NBs. In the context of formation or maintenance of chromatin domains, we propose that DEK plays a critical role in controlling access of histones to DNA.

\section{DEK regulates the $\mathrm{H} 3.3$ balance on chromatin by modulating the interplay between different chaperones}

Incorporation of H3.3 in mammalian cells is carried out by at least two independent complexes, DAXX/ATRX and ASF1A/HIRA/ UBN1/UBN2 (Tagami et al. 2004; Drane et al. 2010; Goldberg et al. 2010; Wong et al. 2010). We now propose a mechanism regulating the distribution of H3.3 between these complexes by DEK. Recruitment of nonnucleosomal H3.3 to PML NBs has been proposed to facilitate H3.3 distribution among histone chaperones in these NBs (Delbarre et al. 2013). We now show that DEK depletion results in the re-routing to chromatin of this nonnucleosomal pool of H3.3, with domain definition dependent on HIRA and on the DAXX/ATRX complex. DEK may thus indirectly influence the allocation of available $\mathrm{H} 3.3$ between different chaperones and hence its site-specific deposition in the genome. This hypothesis is supported by our findings that loss of DEK shifts the H3.3 balance on 
A
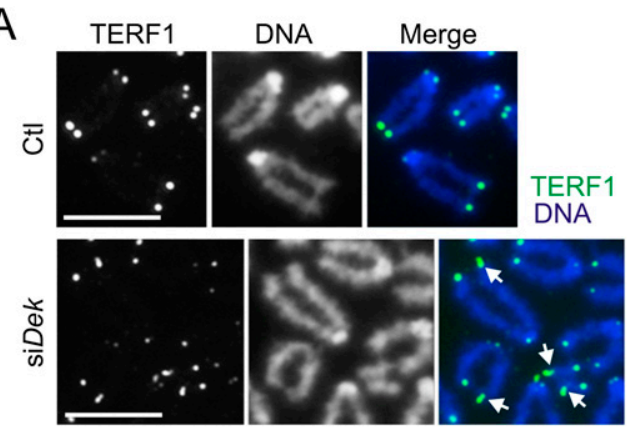

C

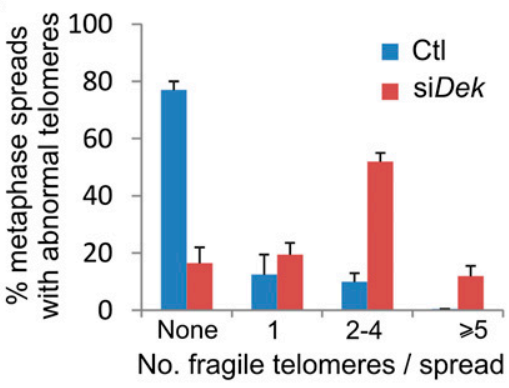

$\mathrm{E}$

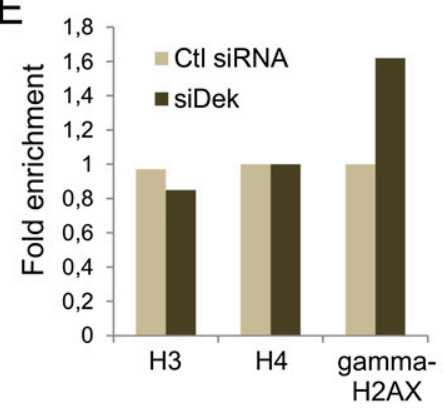

\section{B}
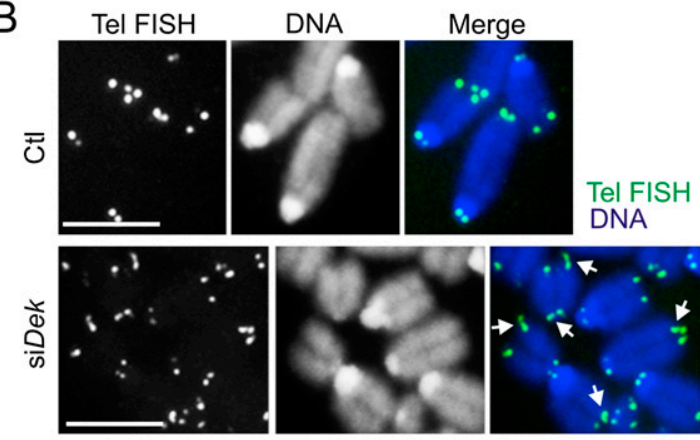

D

TERF1

gamma-H2AX
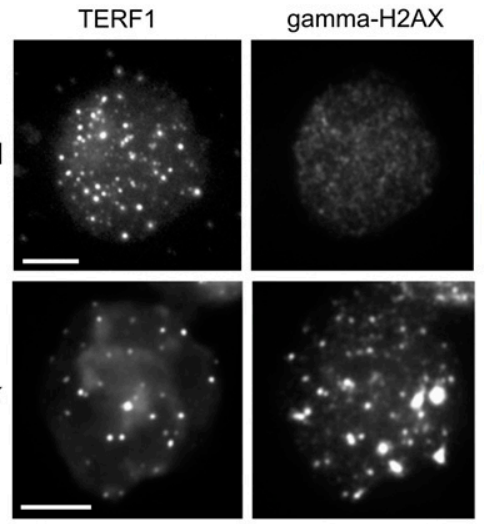

F

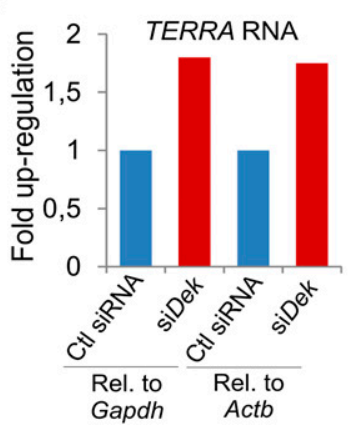

Figure 5. DEK depletion in ESCs induces fragile telomeres. Immunofluorescence detection of TERF1 $(A)$ and telomere FISH analysis of telomere structure (B), on metaphase chromosomes from control and DEK-depleted cells. In control cells, TERF1 and telomere FISH show single signals of similar intensity on both sister chromatid ends. DEK depletion leads to chromatids with double or multiple TERF1 and telomere FISH signals with some stretched signals (arrows). (C) Proportions of metaphase spreads with fragile telomeres induced by DEK depletion (mean \pm SD of three experiments; $n=105$ cells). (D) Immunolocalization of gamma-H2AX in relation to telomeres (TERF1) in control and DEK-depleted cells. Arrows point to telomeres enriched in gamma$\mathrm{H} 2 \mathrm{AX}$. Bars, $5 \mu \mathrm{m}$. (E) ChIP-qPCR analysis of gamma-H2AX enrichment at telomeres in control and DEK-depleted cells (mean fold enrichment of three experiments). Histones $\mathrm{H} 3$ and $\mathrm{H} 4$ were also chromatin immunoprecipitated as controls. ( $F$ ) RT-qPCR analysis of telomere-encoded TERRA RNA transcripts in control and DEK-depleted cells.

chromatin, through a broad deposition on chromosome arms and heterochromatin foci, and defective loading at telomeres.

\section{DEK impacts $\mathrm{H} 3.3$ loading in foci of heterochromatin} associated with PML NBs

In addition to widespread loading of $\mathrm{H} 3.3$ on chromatin, the loss of DEK also promotes H3.3 accumulation in foci of heterochromatin. Interestingly, knockdown of ATRX or DAXX abrogates this accumulation of $\mathrm{H} 3.3$ despite the maintenance of H3K9me3 and CBX3 in these regions; thus we can reasonably exclude that ectopic H3.3 deposition itself initiates local heterochromatinization. Our $P M L$ knockdown data indicate that H3.3-mC targeting and maintenance at these heterochromatin foci do not require PML NBs and that H3.3-mC is incorporated into chromatin at these sites. This distinguishes this particular fraction of H3.3 from H3.3 associated with PML NBs in control (DEK-containing) cells, where its mobility (Delbarre et al. 2013) suggests no chromatin incorporation. The detection of PML in heterochromatin foci in DEK-depleted cells could be due to aggregation of the PML protein at these sites through an unknown mechanism, or to PML recruitment by the DAXX/ATRX complex, given the known association of DAXX with PML (Ishov et al. 1999). Our data favor a scenario where H3.3 is loaded on heterochromatin foci formed after the loss of DEK, or alternatively, where H3.3 accumulates at heterochromatin foci that exist prior to DEK depletion. Either scenario is compatible with recognition of H3K9me3 by ATRX (Dhayalan et al. 2011; Eustermann et al. 2011; Iwase et al. 2011). It is then conceivable 
A Non-telomeric chromatin

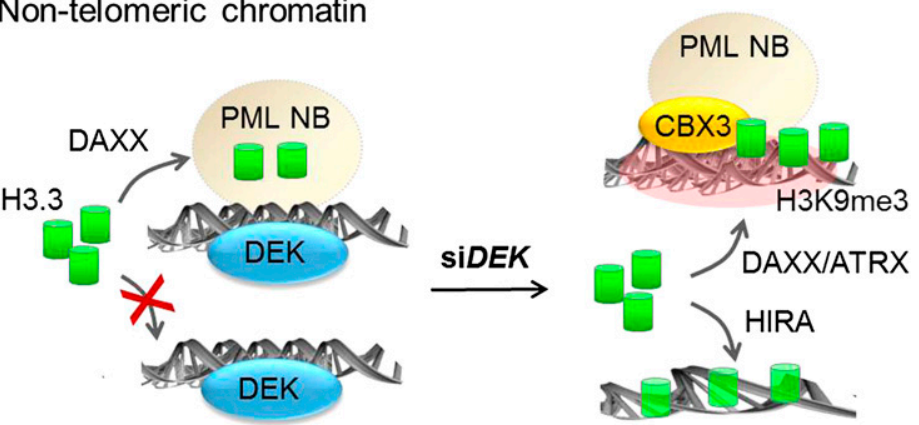

B Telomeric chromatin (ES cells)

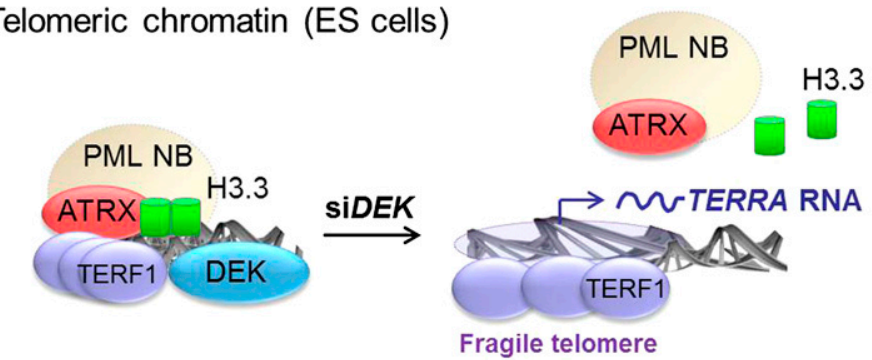

Figure 6. Model of regulation of loading of $\mathrm{H} 3.3$ on chromatin by DEK. (A) Outside telomeres, DEK prevents chromatin loading of nonnucleosomal H3.3, which is recruited to PML NBs by DAXX (Delbarre et al. 2013). Loss of DEK by siRNA relaxes DNA topology and promotes broad HIRA-dependent H3.3 deposition on chromosome arms (lower right) and DAXX/ATRX-dependent loading in H3K9me3- and CBX3-containing heterochromatin foci where PML NBs also aggregate (upper right). (B) At telomeres, DEK has been previously shown to be essential for anchoring of PML NBs and ATRX, enabling H3.3 loading, and this is required to preserve telomere chromatin integrity (Chang et al. 2013). Loss of DEK results in dislocation of PML NBs and ATRX, impairment of H3.3 loading, and a fragile telomere phenotype marked by TERF1 spreading, telomere elongation, and up-regulation of the TERRA long noncoding RNA. The mislocated PML/ATRX/H3.3 complex may be relocated to pericentric heterochromatin.

that DEK restricts H3.3 deposition in heterochromatin by DAXX/ ATRX in a manner analogous to DEK's restriction on H3.3 loading elsewhere in the genome by HIRA.

\section{DEK is important to preserve telomeric chromatin integrity}

Localization of H3.3 chaperones at telomeres in association with PML NBs has been reported in several instances: HIRA and ATRX are observed at telomeres in ESCs, but while H3.3 incorporation at these sites is HIRA-independent, PML NBs appear to tether ATRX and H3.3 at these sites (Wong et al. 2009; Goldberg et al. 2010). We now show that in ESCs DEK is part of the telomere architecture, and is required for association of PML and ATRX, H3.3 loading at telomeres, and maintenance of telomere integrity. Our findings concur with the role of PML in ATRX-dependent H3.3 maintenance at these sites and in preserving telomere function (Chang et al. 2013). We also show that the absence of DEK results in a loss of chromatin repression at telomeres, which may be attributed to a lack of ATRX-mediated H3.3 loading (Goldberg et al. 2010).

Association of DEK with telomeres has been reported in Drosophila (Antao et al. 2012). However, it is important to note that not all telomeres contain DEK in mouse ESCs. DEK localization at telomeres may be linked to their association with PML NBs (Chang et al. 2013). Yet why this only concerns a proportion of telomeres remains unknown but may involve the epigenetic composition of telomeric chromatin, including association with microRNAs (Gonzalo et al. 2006; Benetti et al. 2007, 2008; Chang et al. 2013).

We reveal the functional importance of DEK at telomeres by showing the acquisition of a fragile phenotype in ESCs depleted of DEK. Interestingly, ASF1, another histone chaperone involved in H3.3 deposition, also plays an important role with telomeres. ASF1 helps nucleosome assembly by transferring (H3.3-H4) dimers to HIRA (Tagami et al. 2004), and its depletion results in ALT induction to maintain proliferative capacity (O'Sullivan et al. 2014). DEK and ASF1 are likely involved in different functions at telomeres since DEK depletion does not result in telomeric sister chromatid exchange (LH Wong, unpubl.), contrary to ASF1 depletion (O'Sullivan et al. 2014). We also observe a relocalization of PML from telomeres to pericentric heterochromatin after DEK depletion, whereas ASF1 depletion maintains PML at telomeres (O'Sullivan et al. 2014).

Our results highlight a novel function of DEK as a guardian of chromatin by restricting widespread histone access, and in particular by modulating differential H3.3 loading in specific chromatin areas. Canonical histones (such as H3.1 and H3.2) and $\mathrm{H} 3$ variants such as $\mathrm{H} 3.3$ are subject to post-translational modifications. In genomic sites associated with DEK, inhibition of undesirable H3.3 loading, and associated H3.3 modifications, may be important to preserve the epigenetic landscape. Regulation of H3.3 incorporation by DEK may also impact on nucleosome stability (Henikoff 2008). Our results also suggest that chromatin structure and function depend on the tethering of mechanisms ensuring proper histone supply and routing to various chromatin deposition pathways. Our findings may have implications in the dramatic chromatin remodeling events that take place during embryonic development, stem and progenitor cell differentiation, or cancer development (Broxmeyer et al. 2013).

\section{Methods}

\section{Cells}

MSCs were cultured in DMEM/F12 medium containing GlutaMAX (Gibco) and 20\% fetal calf serum (Delbarre et al. 2013). Mouse ESCs strain ES129.1 were cultured in DMEM/15\% fetal calf serum, essential amino acids, $10^{3} \mathrm{U} / \mathrm{mL}$ of leukemia-inhibiting factor, and $0.1 \mathrm{mM} \beta$-mercaptoethanol. ESCs were induced to differentiate by removal of leukemia inhibitory factor and addition of retinoic acid (Chang et al. 2013).

\section{Transfection of plasmids and siRNAs}

Transfection of mouse ESCs with siRNAs was done using Lipofectamine 2000 (Invitrogen). Mouse Dek siRNAs (DEK ON-target 
Plus siRNA) were from Thermo Scientific. Mouse Hira siRNAs (Mss205135) were from Life Technologies. Transfection of MSCs was done by nucleofection (Delbarre et al. 2013). For expression of proteins in siRNA-treated cells, a first siRNA transfection was followed $96 \mathrm{~h}$ later by a second transfection with both siRNA and the relevant plasmid. Plasmids encoding H3.3-EGFP, H3.3-mCherry, mCherry-PML, and mCherry-DAXX were as described (Delbarre et al. 2013). The EGFP-PML plasmid was a gift from Dr. Harutaka Katano. The EGFP-DEK plasmid was a gift from Dr. Ferdinand Kappes (Kappes et al. 2001). siRNAs to human genes were DEK: CC UUCUGGCAAACCAUUGCCGAAAU; HIRA: GAGCAGAACCUUG UGAAAGAGCUGA; DAXX: GAUCAUCGUGCUCUCAGACUCUG AU; ATRX: GAUAUUGCAGAGAAAUUCCUAAAGA; PML: GGAA GGUCAUCAAGAUGGAGU; Control siRNA: UUCUCCGAACGU GUCACGUTT.

\section{Antibodies}

Antibodies to TERF1 were as described (Iwano et al. 2004), antibodies to PML (5E10) were a gift from Dr. Roel van Driel, human autoimmune serum CREST6 was from the Murdoch Children's Research Institute (Melbourne), and antibodies to CBX3 were from Dr. Brigitte Buendia. The following antibodies were from one or several sources: DAXX (sc-7152, sc-7001), ATRX (sc-15408), DEK (sc-136222): Santa Cruz Biotechnology; DEK (16448-AP): BioSite; TERF2 (05-521), H3K9me3 (05-1250), HIRA (04-1488), H3.3 (09838): Millipore; H3.3S31p (39367): Active Motif; H3K9me3 (pAb056-050): Diagenode; CENPA (2186): Cell Signaling Technologies; PML (ab53773, ab72137, ab50637), H3 (ab1791), H4 (ab10158): Abcam; alpha-tubulin (T5168), FLAG (F1804): Sigma; gammaH2AX (H2AXS139p) (05-636): Millipore; GFP (11814460001): Roche; Alexa Fluor 488 anti-goat (A-11055): Invitrogen; DyLight 549 anti-rabbit (711-505-152). Cy3-, Cy2-, AMCA-, Alexa Fluor 488 anti-mouse-, and HRP-conjugated: Jackson Laboratories. For immunofluorescence, primary antibodies were diluted 1:100 except TERF2 (1:200), DEK (1:50), and CENPA (1:400). Secondary antibodies were diluted 1:200 except DyLight 549 anti-rabbit (1:800) and AMCA-conjugated (1:100). For immunoblotting, antibodies were diluted 1:1000 except CBX3 (1:500), H3 (1:5000), and HRPconjugated (1:7000). A peptide competition assay to assess specificity of the anti-H3.3S31p antibody was done by immunofluorescence analysis as described earlier (Wong et al. 2009).

\section{Immunological procedures}

For immunofluorescence, MSCs were fixed with ice-cold methanol for $6 \mathrm{~min}$, or 3\% paraformaldehyde for $15 \mathrm{~min}$ where indicated, permeabilized with $0.1 \%$ Triton X-100/2\% bovine serum albumin/ $0.01 \%$ Tween 20 , incubated with primary antibodies for $45 \mathrm{~min}$, washed in PBS/0.01\% Tween 20/2\% bovine serum albumin, and incubated with secondary antibodies for $45 \mathrm{~min}$. DNA was stained with $0.1 \mu \mathrm{g} / \mathrm{mL}$ DAPI and coverslips mounted in Mowiol 4-88 (Polysciences). Images were acquired on an Olympus IX71 upright microscope fitted with the DeltaVision system, and processed with ImageJ 1.42q (Delbarre et al. 2013).

ESCs were cultured for $1 \mathrm{~h}$ with colcemid, incubated in $75 \mathrm{mM}$ $\mathrm{KCl}$, spun onto slides, and incubated in $\mathrm{KCM}(120 \mathrm{mM} \mathrm{KCl}, 20 \mathrm{mM}$ $\mathrm{NaCl}, 10 \mathrm{mM}$ Tris-HCl, pH 7.2, 0.5 mM EDTA, 0.1\% Triton X-100, protease inhibitors) followed by $5 \mathrm{~min}$ in $\mathrm{KCM} / 0.5 \%$ Triton X-100 (Chang et al. 2013). Slides were blocked in $\mathrm{KCM} / 1 \%$ bovine serum albumin and incubated with primary and secondary antibodies for $1 \mathrm{~h}$ at $37^{\circ} \mathrm{C}$. Slides were washed $3 \times 5 \mathrm{~min}$ in $\mathrm{KCM}$, fixed in $\mathrm{KCM} /$ $4 \%$ formaldehyde. DNA was stained with DAPI and slides mounted in Vectashield. Immunofluorescence analyses and image process- ing were done using a Zeiss Axioimager.M1 microscope/AxioCam MRm camera and the AxioVs40v4.6.1.0 software.

PML or DEK was immunoprecipitated from MSC cell lysates prepared by probe sonication in $20 \mathrm{mM}$ Tris- $\mathrm{HCl}(\mathrm{pH} 7.5), 150$ $\mathrm{mM} \mathrm{NaCl}, 1 \mathrm{mM}$ EDTA, 1 mM EGTA, 1\% Triton X-100, and protease inhibitors. The lysate was sedimented at $10,000 \mathrm{~g}$ for $15 \mathrm{~min}$ at $4^{\circ} \mathrm{C}$ and the supernatant used for immunoprecipitation using anti-PML $(10 \mu \mathrm{g})$ or anti-DEK $(3 \mu \mathrm{g})$ antibodies after preclearing with Protein G Dynabeads. Immune complexes were washed five times in PBS/0.1\% Triton X-100 and dissolved in SDS sample buffer prior to SDS-PAGE. Western blotting was done as described after resolving samples by $4 \%-20 \%$ SDS-PAGE (Delbarre et al. 2013).

\section{Fluorescence recovery after photobleaching (FRAP)}

FRAP was done in a $\sim 2-\mu \mathrm{m}$ diameter area using a SuperApochromat $60 \times / 1.35$ objective and an Olympus confocal microscope fitted with a SIM scanner as described (Delbarre et al. 2013). Forty-eight hours after transfection of H3.3-EGFP, FRAP images were taken every $10 \mathrm{sec}$, with the first acquisition taken $10 \mathrm{sec}$ before bleaching. Data analysis including measures and normalization was as described previously (Delbarre et al. 2013).

\section{Fluorescence in situ hybridization (FISH)}

For telomere FISH (Chang et al. 2013), ESCs treated with colcemid were suspended in $75 \mathrm{mM} \mathrm{KCl}$, fixed in ice-cold methanol:acetic acid (3:1), dropped onto slides and air-dried. Slides were dehydrated in $70 \%, 95 \%, 100 \%$ ethanol series, denatured in $70 \%$ formamide $/ 2 \times \mathrm{SSC}$ at $70^{\circ} \mathrm{C}$, and hybridized with a Cy3-conjugated telomere DNA probe (PNA Bio) in 50\% formamide, $0.5 \%$ blocking reagent (Gibco), and $10 \mathrm{mM}$ Tris- $\mathrm{HCl}, \mathrm{pH}$ 7.2.

\section{Reverse transcription PCR}

Total RNA was isolated and DNase-treated before cDNA synthesis (High-Capacity cDNA Reverse Transcription Kit; Applied Biosystems). Real-time PCR was done using SYBR Green in a Roche Light Cycler Real-Time PCR System. Data were analyzed using the $\Delta \mathrm{C}_{\mathrm{T}}$ method after normalization against $\mathrm{C}_{\mathrm{T}}$ values for Gapdh and $A c t b$. Relative fold difference in RNA level was expressed as $2^{-\Delta \Delta C T}$. TERRA primers were 5'-GGTTTTTGAGGGTGAGGGTGAGGGT GAGGGTGAGGGT-3' and 5'-TCCCGACTATCCCTATCCCTAT CCСТATCССТATCCCTA-3'. Actb primers were $5^{\prime}$-TCCCTGGAG AAGAGCTACGA-3' and 5' -AGCACTGTGTTGGCGTACAG-3' , and Gapdh primers were 5'-AAGTATGATGACATCAAGAAGGTCCT-3' and 5'-AGCCCAGGATGCCCTTTAGT-3'.

\section{Cell and chromatin fractionation}

After collection, cells were lysed for $20 \mathrm{~min}$ at $4^{\circ} \mathrm{C}$ in digestion buffer (250 mM sucrose, $50 \mathrm{mM}$ Tris- $\mathrm{HCl} \mathrm{pH} \mathrm{7.5,5} \mathrm{mM} \mathrm{MgCl}_{2}$, $1 \mathrm{mM} \mathrm{CaCl}_{2}, 5 \mathrm{mM}$ Na-butyrate, $1 \mathrm{mM}$ DTT, $1 \mathrm{mM}$ PMSF, and protease inhibitors) containing $0.5 \%$ Triton X-100. After sedimentation, the supernatant (S1 fraction) was collected. The pellet was washed in digestion buffer and resuspended in digestion buffer containing 0.167 units of MNase (Sigma-Aldrich) per $\mu$ g DNA for $10 \mathrm{~min}$ at $37^{\circ} \mathrm{C}$. Digestion was stopped by addition of EDTA to $5 \mathrm{mM}$, and the MNase-soluble nucleosomal fraction (S2) was recovered after sedimentation at $11000 \mathrm{~g}$ for $10 \mathrm{~min}$ at $4^{\circ} \mathrm{C}$. DNA was recovered by methanol-chloroform-isoamyl alcohol extraction from aliquots of the S1, S2, and P2 (MNase-insoluble) fractions to assess digestion (data not shown). Proteins were purified from the 
same fractions, from the water-soluble phase after extraction with methanol-chloroform-isoamyl alcohol, and resolved by $4 \%-20 \%$ gradient SDS-PAGE.

\section{Chromatin immunoprecipitation}

Cells were harvested, crosslinked with $1 \%$ paraformaldehyde for $10 \mathrm{~min}$, and quenched by adding glycine to $0.25 \mathrm{M}$. Cells were washed in PBS and lysed in $10 \mathrm{mM}$ Tris $\mathrm{pH} 8,10 \mathrm{mM} \mathrm{NaCl}$, and $0.2 \% \mathrm{NP} 40$. Nuclei were sedimented and resuspended in $50 \mathrm{mM}$

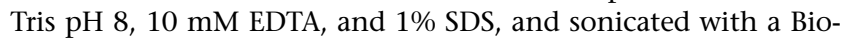
ruptor (Diagenode) to obtain chromatin fragments of $\leq 500 \mathrm{bp}$. Chromatin was diluted in $20 \mathrm{mM}$ Tris $\mathrm{pH} 8,2 \mathrm{mM}$ EDTA, $150 \mathrm{mM}$ $\mathrm{NaCl}, 1 \%$ Triton $\mathrm{X}-100$, and $0.01 \%$ SDS, and precleared with Protein $\mathrm{G}$ magnetic beads at $4^{\circ} \mathrm{C}$. Precleared chromatin was immunoprecipitated with antibody-bound beads at $4^{\circ} \mathrm{C}$ overnight. After washes, ChIP DNA was eluted, treated with RNase A and Proteinase $\mathrm{K}$, and reverse crosslinked at $65^{\circ} \mathrm{C}$ overnight. DNA was extracted with phenol-chloroform and precipitated using tRNA and glycogen as carriers. Quantitative PCR was done using the following primers: 5'-GGTTTTTGAGGGTGAGGGTGAGGG TGAGGGTGAGGGT-3' and 5'-TCCCGACTATCCCTATCCCTA TCCCTATCCCTATCCCTA-3'.

\section{Acknowledgments}

We thank Dr. Roel van Driel (University of Amsterdam) for PML antibodies, Dr. Brigitte Buendia (Université Paris Diderot, Paris) for CBX3 antibodies, the Murdoch Children's Research Institute (Melbourne) for the CREST6 autoimmune serum, Dr. Ferdinand Kappes (RWTH Aachen University) for the EGFP-DEK plasmid, and Dr. Harutaka Katano (National Institute of Infectious Diseases, Toyama) for the EGFP-PML plasmid. This work was funded by the Research Council of Norway, the Norwegian Center for Stem Cell Research, the Norwegian Cancer Society and South-East Health Norway (P.C.), the National Health and Medical Research Council of Australia (NHMRC), and Victoria Government's Operational Infrastructure Support program (L.H.W.). L.H.W. is a recipient of a Career Development Award from the NHMRC.

\section{References}

Adam S, Polo SE, Almouzni G. 2013. Transcription recovery after DNA damage requires chromatin priming by the H3.3 histone chaperone HIRA. Cell 155: 94-106.

Alexiadis V, Waldmann T, Andersen J, Mann M, Knippers R, Gruss C. 2000. The protein encoded by the proto-oncogene DEK changes the topology of chromatin and reduces the efficiency of DNA replication in a chromatin-specific manner. Genes Dev 14: 1308-1312.

Antao JM, Mason JM, Dejardin J, Kingston RE. 2012. Protein landscape at Drosophila melanogaster telomere-associated sequence repeats. Mol Cell Biol 32: 2170-2182.

Argentaro A, Yang JC, Chapman L, Kowalczyk MS, Gibbons RJ, Higgs DR, Neuhaus D, Rhodes D. 2007. Structural consequences of disease-causing mutations in the ATRX-DNMT3-DNMT3L (ADD) domain of the chromatin-associated protein ATRX. Proc Natl Acad Sci 104: 11939_ 11944.

Banaszynski LA, Wen D, Dewell S, Whitcomb SJ, Lin M, Diaz N, Elsasser SJ, Chapgier A, Goldberg AD, Canaani E, et al. 2013. Hira-dependent histone H3.3 deposition facilitates PRC2 recruitment at developmental loci in ES cells. Cell 155: 107-120.

Benetti R, Gonzalo S, Jaco I, Schotta G, Klatt P, Jenuwein T, Blasco MA. 2007. Suv4-20h deficiency results in telomere elongation and derepression of telomere recombination. J Cell Biol 178: 925-936.

Benetti R, Gonzalo S, Jaco I, Munoz P, Gonzalez S, Schoeftner S, Murchison E, Andl T, Chen T, Klatt P, et al. 2008. A mammalian microRNA cluster controls DNA methylation and telomere recombination via Rbl2dependent regulation of DNA methyltransferases. Nat Struct Mol Biol 15: 998.
Bernardi R, Pandolfi PP. 2007. Structure, dynamics and functions of promyelocytic leukaemia nuclear bodies. Nat Rev Mol Cell Biol 8: 10061016.

Bohm F, Kappes F, Scholten I, Richter N, Matsuo H, Knippers R, Waldmann T. 2005. The SAF-box domain of chromatin protein DEK. Nucleic Acids Res 33: 1101-1110.

Broxmeyer HE, Mor-Vaknin N, Kappes F, Legendre M, Saha AK, Ou X, O'Leary H, Capitano M, Cooper S, Markovitz DM. 2013. Concise review: role of DEK in stem/progenitor cell biology. Stem Cells 31: 1447-1453.

Chang FT, McGhie JD, Chan FL, Tang MC, Anderson MA, Mann JR, Andy Choo KH, Wong LH. 2013. PML bodies provide an important platform for the maintenance of telomeric chromatin integrity in embryonic stem cells. Nucleic Acids Res 41: 4447-4458.

Ching RW, Ahmed K, Boutros PC, Penn LZ, Bazett-Jones DP. 2013. Identifying gene locus associations with promyelocytic leukemia nuclear bodies using immuno-TRAP. J Cell Biol 201: 325-335.

de Thé H, Le Bras M, Lallemand-Breitenbach V. 2012. The cell biology of disease: acute promyelocytic leukemia, arsenic, and PML bodies. J Cell Biol 198: 11-21.

Delbarre E, Ivanauskiene K, Kuntziger T, Collas P. 2013. DAXX-dependent supply of soluble (H3.3-H4) dimers to PML bodies pending deposition into chromatin. Genome Res 23: 440-451.

Dhayalan A, Tamas R, Bock I, Tattermusch A, Dimitrova E, Kudithipudi S, Ragozin S, Jeltsch A. 2011. The ATRX-ADD domain binds to H3 tail peptides and reads the combined methylation state of K4 and K9. Hum Mol Genet 20: 2195-2203.

Dinkel H, Van RK, Michael S, Davey NE, Weatheritt RJ, Born D, Speck T, Kruger D, Grebnev G, Kuban M, et al. 2014. The eukaryotic linear motif resource ELM: 10 years and counting. Nucleic Acids Res 42: D259-D266.

Drane P, Ouararhni K, Depaux A, Shuaib M, Hamiche A. 2010. The deathassociated protein DAXX is a novel histone chaperone involved in the replication-independent deposition of H3.3. Genes Dev 24: 1253-1265.

Elsaesser SJ, Allis CD. 2010. HIRA and Daxx constitute two independent histone H3.3-containing predeposition complexes. Cold Spring Harb Symp Quant Biol 75: 27-34.

Eustermann S, Yang JC, Law MJ, Amos R, Chapman LM, Jelinska C, Garrick D, Clynes D, Gibbons RJ, Rhodes D, et al. 2011. Combinatorial readout of histone $\mathrm{H} 3$ modifications specifies localization of ATRX to heterochromatin. Nat Struct Mol Biol 18: 777-782.

Filipescu D, Szenker E, Almouzni G. 2013. Developmental roles of histone H3 variants and their chaperones. Trends Genet 29: 630-640.

Gibbons RJ, Bachoo S, Picketts DJ, Aftimos S, Asenbauer B, Bergoffen J, Berry SA, Dahl N, Fryer A, Keppler K, et al. 1997. Mutations in transcriptional regulator ATRX establish the functional significance of a PHD-like domain. Nat Genet 17: 146-148.

Goldberg AD, Banaszynski LA, Noh KM, Lewis PW, Elsaesser SJ, Stadler S, Dewell S, Law M, Guo X, Li X, et al. 2010. Distinct factors control histone variant H3.3 localization at specific genomic regions. Cell 140: 678-691.

Gonzalo S, Jaco I, Fraga MF, Chen T, Li E, Esteller M, Blasco MA. 2006. DNA methyltransferases control telomere length and telomere recombination in mammalian cells. Nat Cell Biol 8: 416-424.

Henikoff S. 2008. Nucleosome destabilization in the epigenetic regulation of gene expression. Nat Rev Genet 9: 15-26.

Hollenbach AD, McPherson CJ, Mientjes EJ, Iyengar R, Grosveld G. 2002. Daxx and histone deacetylase II associate with chromatin through an interaction with core histones and the chromatin-associated protein Dek. J Cell Sci 115: 3319-3330.

Ishov AM, Sotnikov AG, Negorev D, Vladimirova OV, Neff N, Kamitani T, Yeh ET, Strauss JF III, Maul GG. 1999. PML is critical for ND10 formation and recruits the PML-interacting protein daxx to this nuclear structure when modified by SUMO-1. I Cell Biol 147: 221-234.

Iwano T, Tachibana M, Reth M, Shinkai Y. 2004. Importance of TRF1 for functional telomere structure. J Biol Chem 279: 1442-1448.

Iwase S, Xiang B, Ghosh S, Ren T, Lewis PW, Cochrane JC, Allis CD, Picketts DJ, Patel DJ, Li H, et al. 2011. ATRX ADD domain links an atypical histone methylation recognition mechanism to human mentalretardation syndrome. Nat Struct Mol Biol 18: 769-776.

Jiang WQ, Nguyen A, Cao Y, Chang AC, Reddel RR. 2011. HP1-mediated formation of alternative lengthening of telomeres-associated PML bodies requires HIRA but not ASF1a. PLOS ONE 6: e17036.

Kappes F, Burger K, Baack M, Fackelmayer FO, Gruss C. 2001. Subcellular localization of the human proto-oncogene protein DEK. J Biol Chem 276: 26317-26323.

Kappes F, Waldmann T, Mathew V, Yu J, Zhang L, Khodadoust MS, Chinnaiyan AM, Luger K, Erhardt S, Schneider R, et al. 2011. The DEK oncoprotein is a $\mathrm{Su}(\mathrm{var})$ that is essential to heterochromatin integrity. Genes Dev 25: 673-678.

Kavanaugh GM, Wise-Draper TM, Morreale RJ, Morrison MA, Gole B, Schwemberger S, Tichy ED, Lu L, Babcock GF, Wells JM, et al. 2011. The human DEK oncogene regulates DNA damage response signaling and repair. Nucleic Acids Res 39: 7465-7476. 
Lallemand-Breitenbach V, Zhu J, Puvion F, Koken M, Honore N, Doubeikovsky A, Duprez E, Pandolfi PP, Puvion E, Freemont P, et al. 2001. Role of promyelocytic leukemia (PML) sumolation in nuclear body formation, $11 \mathrm{~S}$ proteasome recruitment, and As2O3-induced PML or PML/retinoic acid receptor $\alpha$ degradation. I Exp Med 193: 1361-1371.

Lewis PW, Elsaesser SJ, Noh KM, Stadler SC, Allis CD. 2010. Daxx is an H3.3specific histone chaperone and cooperates with ATRX in replicationindependent chromatin assembly at telomeres. Proc Natl Acad Sci 107: 14075-14080.

Luke B, Lingner J. 2009. TERRA: telomeric repeat-containing RNA. EMBO J 28: $2503-2510$.

O'Sullivan RJ, Arnoult N, Lackner DH, Oganesian L, Haggblom C, Corpet A, Almouzni G, Karlseder J. 2014. Rapid induction of alternative lengthening of telomeres by depletion of the histone chaperone ASF1. Nat Struct Mol Biol 21: 167-174.

Obri A, Ouararhni K, Papin C, Diebold ML, Padmanabhan K, Marek M, Stoll I, Roy L, Reilly PT, Mak TW, et al. 2014. ANP32E is a histone chaperone that removes H2A.Z from chromatin. Nature 505: 648-653.

Pchelintsev NA, McBryan T, Rai TS, van Tuyn J, Ray-Gallet D, Almouzni G, Adams PD. 2013. Placing the HIRA histone chaperone complex in the chromatin landscape. Cell Rep 3: 1012-1019.

Privette Vinnedge LM, Kappes F, Nassar N, Wells SI. 2013. Stacking the DEK: from chromatin topology to cancer stem cells. Cell Cycle 12: 51-66.

Ray-Gallet D, Woolfe A, Vassias I, Pellentz C, Lacoste N, Puri A, Schultz DC, Pchelintsev NA, Adams PD, Jansen LE, et al. 2011. Dynamics of histone H3 deposition in vivo reveal a nucleosome gap-filling mechanism for H3.3 to maintain chromatin integrity. Mol Cell 44: 928-941.

Saha AK, Kappes F, Mundade A, Deutzmann A, Rosmarin DM, Legendre M, Chatain N, Al-Obaidi Z, Adams BS, Ploegh HL, et al. 2013. Intercellular trafficking of the nuclear oncoprotein DEK. Proc Natl Acad Sci 110: 6847-6852.

Sawatsubashi S, Murata T, Lim J, Fujiki R, Ito S, Suzuki E, Tanabe M, Zhao Y, Kimura S, Fujiyama S, et al. 2010. A histone chaperone, DEK, transcriptionally coactivates a nuclear receptor. Genes Dev 24: 159_ 170 .
Schneiderman JI, Orsi GA, Hughes KT, Loppin B, Ahmad K. 2012. Nucleosome-depleted chromatin gaps recruit assembly factors for the H3.3 histone variant. Proc Natl Acad Sci 109: 19721-19726.

Sfeir A, Kosiyatrakul ST, Hockemeyer D, MacRae SL, Karlseder J, Schildkraut CL, de Lange T. 2009. Mammalian telomeres resemble fragile sites and require TRF1 for efficient replication. Cell 138: 90-103.

Sigrist CJ, de Castro E, Cerutti L, Cuche BA, Hulo N, Bridge A, Bougueleret L, Xenarios I. 2013. New and continuing developments at PROSITE. Nucleic Acids Res 41: D344-D347.

Szenker E, Ray-Gallet D, Almouzni G. 2011. The double face of the histone variant H3.3. Cell Res 21: 421-434.

Tagami H, Ray-Gallet D, Almouzni G, Nakatani Y. 2004. Histone H3.1 and H3.3 complexes mediate nucleosome assembly pathways dependent or independent of DNA synthesis. Cell 116: 51-61.

Talbert PB, Henikoff S. 2010. Histone variants-ancient wrap artists of the epigenome. Nat Rev Mol Cell Biol 11: 264-275.

Waldmann T, Eckerich C, Baack M, Gruss C. 2002. The ubiquitous chromatin protein DEK alters the structure of DNA by introducing positive supercoils. J Biol Chem 277: 24988-24994.

Waldmann T, Baack M, Richter N, Gruss C. 2003. Structure-specific binding of the proto-oncogene protein DEK to DNA. Nucleic Acids Res 31: 70037010.

Waldmann T, Scholten I, Kappes F, Hu HG, Knippers R. 2004. The DEK protein-an abundant and ubiquitous constituent of mammalian chromatin. Gene 343: 1-9.

Wong LH, Ren H, Williams E, McGhie J, Ahn S, Sim M, Tam A, Earle E, Anderson MA, Mann J, et al. 2009. Histone H3.3 incorporation provides a unique and functionally essential telomeric chromatin in embryonic stem cells. Genome Res 19: 404-414.

Wong LH, McGhie JD, Sim M, Anderson MA, Ahn S, Hannan RD, George AJ, Morgan KA, Mann JR, Choo KH. 2010. ATRX interacts with H3.3 in maintaining telomere structural integrity in pluripotent embryonic stem cells. Genome Res 20: 351-360.

Received February 19, 2014; accepted in revised form July 18, 2014. 


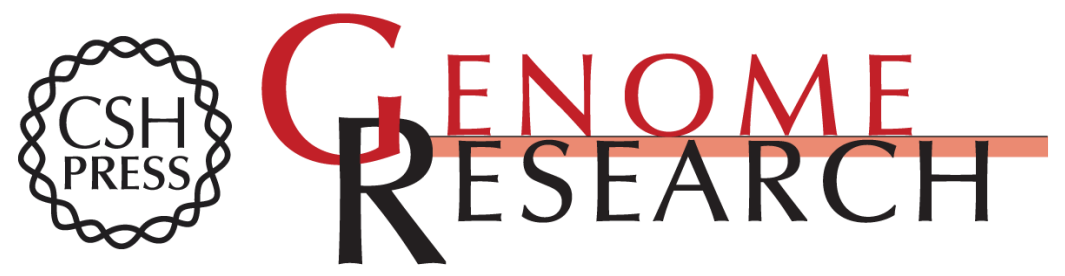

\section{The PML-associated protein DEK regulates the balance of H3.3 loading on chromatin and is important for telomere integrity}

Kristina Ivanauskiene, Erwan Delbarre, James D. McGhie, et al.

Genome Res. 2014 24: 1584-1594 originally published online July 21, 2014

Access the most recent version at doi:10.1101/gr.173831.114

Supplemental Material

References

Creative

Commons

License

Email Alerting Service
http://genome.cshlp.org/content/suppl/2014/08/07/gr.173831.114.DC1

This article cites 53 articles, 23 of which can be accessed free at: http://genome.cshlp.org/content/24/10/1584.full.html\#ref-list-1

This article is distributed exclusively by Cold Spring Harbor Laboratory Press for the first six months after the full-issue publication date (see

http://genome.cshlp.org/site/misc/terms.xhtml). After six months, it is available under a Creative Commons License (Attribution-NonCommercial 4.0 International), as described at http://creativecommons.org/licenses/by-nc/4.0/.

Receive free email alerts when new articles cite this article - sign up in the box at the top right corner of the article or click here.

\section{Affordable, Accurate Sequencing.}

To subscribe to Genome Research go to:

https://genome.cshlp.org/subscriptions 